Article

\title{
A Highly Efficient and Durable Fluorescent Paper Produced from Bacterial Cellulose/Eu Complex and Cellulosic Fibers
}

\author{
Mingquan Zhang ${ }^{1}$, Xiao $\mathrm{Wu}^{1}$, Zhenhua $\mathrm{Hu}^{1}{ }^{1}$, Zhouyang Xiang ${ }^{1, *} *$, Tao Song ${ }^{1}$ and \\ Fachuang $\mathrm{Lu}^{1,2, *}$ \\ 1 State Key Laboratory of Pulp and Paper Engineering, South China University of Technology, \\ Guangzhou 510640, China; fezhangmingquan@mail.scut.edu.cn (M.Z.); msxiaowu@mail.scut.edu.cn (X.W.); \\ zhenhuahu1991@163.com (Z.H.); songt@scut.edu.cn (T.S.) \\ 2 Guangdong Engineering Research Center for Green Fine Chemicals, Guangzhou 510640, China \\ * Correspondence: fezyxiang@scut.edu.cn (Z.X.); fefclv@scut.edu.cn (F.L.)
}

Received: 12 August 2019; Accepted: 12 September 2019; Published: 15 September 2019

check for updates

\begin{abstract}
The general method of producing fluorescent paper by coating fluorescent substances onto paper base faces the problems of low efficiency and poor durability. Bacterial cellulose (BC) with its nanoporous structure can be used to stabilize fluorescent particles. In this study, we used a novel method to produce fluorescent paper by first making $\mathrm{Eu} / \mathrm{BC}$ complex and then processing the complex and cellulosic fibers into composite paper sheets. For this composting method, BC can form very stable $\mathrm{BC} / \mathrm{Eu}$ complex due to its nanoporous structure, while the plant-based cellulosic fibers reduce the cost and provide stiffness to the materials. The fluorescent paper demonstrated a great fluorescent property and efficiency. The ultraviolet absorbance or the fluorescent intensity of the Eu-BC fluorescent paper increased with the increase of Eu-BC content but remained little changed after Eu-BC content was higher than 5\%. After folding 200 times, the fluorescence intensity of fluorescent paper decreased by only $0.7 \%$, which suggested that the Eu-BC fluorescent paper has great stability and durability.
\end{abstract}

Keywords: bacterial cellulose; Eu ion; complex; cellulosic fiber; fluorescent paper; durability

\section{Introduction}

Europium $(\mathrm{Eu})$ element has one of the best photoluminescent properties among rare earth elements. Due to the $4 \mathrm{f} \rightarrow 4 \mathrm{f}$ transition, $\mathrm{Eu}^{3+}$ ions can convert ultraviolet light into visible light and have been widely used in fluoroimmunoassay [1,2]. The antenna effect induced by the chelation between $\mathrm{Eu}^{3+}$ and negatively charged ligand results in an even stronger photoluminescent performance for ligand/ $\mathrm{Eu}^{3+}$ complexes. The complexes of various ligands, e.g., $\beta$-diketone, chelated with $\mathrm{Eu}^{3+}$ can be used as photoreceptors, superconductors, magnetic materials, catalysts, fluorescent probes, and light-emitting diodes [3-8].

Complexes of polymer ligands and rare earth elements are considered as high-efficiency light-emitting materials because of their strong photoluminescent ability, easy color mixing, low temperature sensitivity, and high thermal stability [9]. In the complex of cholesterol-g-poly ( $N$-isopropylacrylamide) (PNIPAM) and $\mathrm{Eu}^{3+}$, the oxygen-nitrogen coordination between amide group and $\mathrm{Eu}^{3+}$ provides a strong fluorescent characteristic for $\mathrm{Eu}^{3+}$ [10]. Those ligands with functional groups containing strong electron-donating groups, e.g., hydroxyls, carboxyls, amides, and nitriles, especially have strong chelation effects with $\mathrm{Eu}^{3+}$ ions or other rare earth elements. Carboxymethyl cellulose (CMC) or cholesterol-g-poly(N-isopropylacrylamide) were used to complex with Eu or Tb, and they showed strong photofluorescent properties [11-14]. Hybridized nanofibers were produced between polyacrylonitrile and $\mathrm{Eu}^{3+}$, which had one-dimensional nanostructure and high specific surface area, showing excellent fluorescent properties [1]. However, most of these photofluorescent complexes 
or materials are still facing the problems of stability and durability, i.e., the fluorescence intensity decreases after severe use, due to the leaching or aggregation of fluorescent elements or particles.

When the polymer ligands reduce to nano- or submicron-scale, they provide the materials with special characteristics in mechanical, optical, thermal, or surface properties [15]. Nanocellulose, with its sustainable nature and nanoscale characteristics, inspires its application in functional materials. So far, only a few studies have used nanocellulose, e.g., cellulose nanocrystal (CNC), cellulose nanofibril (CNF), and bacterial cellulose (BC), as supports or ligands for fluorescent substances. Fluorescein-5'-isothiocyanate (FITC) was used to label CNCs for fluorescence bioassay and bio-imaging applications [16]. CNCs grafted by poly (N-isopropylacryalamide)(PNIPAAM) brushes had thermo-enhanced fluorescence and can be used in biomedical applications [17]. The silver nanocluster was loaded on natural CNFs, giving the material fluorescence properties and antimicrobial properties [18]. A fluorescent film was prepared by chemical modification of CNF film surface with boronate-terminated conjugated polymer chains and used to detect nitro-aromatic vapor [19].

Bacterial cellulose (BC) is a type of typical extracellular cellulose produced by acetobacter bacteria. $\mathrm{BC}$ was composed of ultrafine and interlaced nanofibers with a width of less than $100 \mathrm{~nm}$ to form a network structure. This structural feature provides BC with a large specific surface area and a nanoporous structure [20,21]. This nanoporous structure makes BC an ideal support for functional nanoparticles that can be further processed into functional materials. $\mathrm{BC}$ membranes were used to support $\mathrm{TiO}_{2}$ nanoparticles and blended with rare earth elements, e.g., lanthanum (La) and cerium (Ce), leading to a high photocatalytic efficiency [22]. BC and CdSe were combined to prepare composite films which have photoluminescence properties [23]. BC was used to support nitrogen-doped carbon nanofibers; this composite showed electrode material properties and was used to prepare a flexible all-solid-state high-power supercapacitor [24]. Pt was supported by BC to prepare a composite material having high catalytic efficiency for methanol fuel battery [25]. There are very few studies on the preparation of photofluorescent materials by using $\mathrm{BC}$ to support and form complexes with rare earth elements. The possible reason is the high cost of $\mathrm{BC}$ and its soft nature upon film forming, which is not able to provide a good stiffness for the materials.

Plant-based cellulosic fibers are well known to be the raw material for paper making and they can also be used as substrates or supporting materials for functional ligands to produce functional paper-based materials. Fluorescent paper has also been produced. Coating or printing method is a common way to composite the fluorescent materials with paper sheets. Fluorescent DNA-based oligodeoxyfluoroside dyes were printed on paper, which can sense food spoilage and ripening in the vapor phase [26]. 8-hydroxyquinoline aluminum (Alq3)-based bluish green fluorescent composite nanospheres were printed on paper as sensors for nitroaromatic explosive detection [27]. A ratiometric fluorescent probe-based paper sensor based on paper printed with gold nanoclusters stabilized by bovine serum albumin and fluorescent graphene oxide can be used for the determination of serum blood sugar [28]. Fluorescent inks such as heterorotaxane and the mixture of triethanolamine and UV absorbent UV-7282 were also used to print on paper for fluorescence $[29,30]$. Fluorescein isothiocyanate (FITC) and thioflavin were absorbed by nanocellulose and that was coated on the surface of paper to prepare fluorescent paper [31]. Most of the current methods produce fluorescent paper by attaching fluorescent materials to the surface of paper without altering the paper fiber structure. However, common cellulosic fibers do not have nanoporous structure and thus cannot well stabilize the nanosized fluorescent particles, leading to lack of stability, recycling efficiency, and durability.

BC can be tightly bound to cellulosic fibers due to their abundant surface hydroxyl groups [20,21], whose features can be used to prepare functional paper-based materials if $\mathrm{BC}$ is properly functionalized. In cellulosic fiber/BC composite functional materials, cellulosic fibers can reduce the cost of pure $\mathrm{BC}$ materials and provide high stiffness, while $\mathrm{BC}$ can still provide the materials with high toughness, high tearing, good stability, and durability. Catalytic paper sheets were produced by loading Pt or $\mathrm{Au}$ onto $\mathrm{BC}$ surface and then compositing with cellulosic fibers, which showed excellent catalytic efficiency, stability, and reusability [32,33]. In this study, we prepared fluorescent paper by making 
$\mathrm{BC} / \mathrm{Eu}$ complex first and then processing the complex and cellulosic fibers into paper sheets. This method incorporates the fluorescent complexes as part of the cellulosic fiber matrix and thus may improve the stability and durability of fluorescent paper.

\section{Materials and Methods}

\subsection{Materials}

Gluconacetobacter xylinus ATCC23767 was obtained from Nanjing High Tech University Biological Technology Research Institute Co., Ltd. (Nanjing, China) and used to produce the bacterial cellulose (BC) pellicles according to the static fermentation method [20,21]. The degree of polymerization (DP) and Segal crystallinity index (CI) of BC was predetermined as 1081 and $96.0 \%$, respectively [20,21].

Europium trioxide $\left(\mathrm{Eu}_{2} \mathrm{O}_{3}\right)$, hydrochloric acid, and sodium hydroxide were purchased from Shanghai Macklin Biochemical Co., Ltd. (Shanghai, China). All other chemicals are analytical grade chemicals.

\subsection{Preparation of $\mathrm{EuCl}_{3} \cdot 6 \mathrm{H}_{2} \mathrm{O}$}

$\mathrm{Eu}_{2} \mathrm{O}_{3}(0.727 \mathrm{~g})$ was completely dissolved in $6.0 \mathrm{~mol} / \mathrm{L} \mathrm{HCl}$ solution. The mixture was placed in boiling water bath for $30 \mathrm{~min}$ to evaporate the unreacted $\mathrm{HCl}$. The solution was then diluted with deionized water to volume $100 \mathrm{~mL}$ to adjust the concentration to $0.0416 \mathrm{~mol} / \mathrm{L}$.

\subsection{Preparation of Eu-BC}

Approximately $20 \mathrm{~g}$ of wet BC pellicles (moisture content $=98.5 \%$ ) was disintegrated by a lab homogenizer (SKG 1246, Foshan, China) for $20 \mathrm{~s}$ in $130 \mathrm{~mL}$ of water. The water was then filtered to obtain the disintegrated $\mathrm{BC}$. The $\mathrm{pH}$ of the $\mathrm{EuCl}_{3} \cdot 6 \mathrm{H}_{2} \mathrm{O}$ solution was adjusted to 5-6 with $1 \mathrm{M} \mathrm{NaOH}$. The disintegrated $\mathrm{BC}$ was then added slowly to the $\mathrm{EuCl}_{3} \cdot 6 \mathrm{H}_{2} \mathrm{O}$ solution at $45^{\circ} \mathrm{C}$ under a magnetic stirring (400 rpm). The $\mathrm{pH}$ of mixture was adjusted to about 7 with $1 \mathrm{M} \mathrm{NaOH}$. Finally, the mixture was refluxed at $70{ }^{\circ} \mathrm{C}$ for $1 \mathrm{~h} 30 \mathrm{~min}$ to prepare Eu-BC.

\subsection{Manufacture of Fluorescent Paper}

A vacuum filtering method was used to prepare the fluorescent paper because at high EuBC addition it would take a very long time at the water drainage step for the standard TAPPI method. In detail, bleached sugarcane bagasse pulps (BSBP) and Eu-BC were composited with different ratios, i.e., $1 \%, 2 \%, 5 \%, 10 \%$, and $20 \%$ (the proportion of Eu-BC based on total paper dry weight). The mixture was homogenizer for $20 \mathrm{~s}$ and the mixture was filtered by a sand core filter device. After water was drained, the paper sheet was formed. Finally, the paper was dried in an oven at $9{ }^{\circ} \mathrm{C}$ for $50 \mathrm{~min}$.

\subsection{Characterization of Eu-BC and Fluorescent Paper}

Nitrogen adsorption-desorption isotherm measurements were performed on an ASAP 2460 (Micromeritics, Norcross, GA, USA) volumetric adsorption analyzer at $77 \mathrm{~K}$. The Brunauer-EmmettTeller (BET) method was utilized to calculate the specific surface area of each sample. All samples were degassed at $120{ }^{\circ} \mathrm{C}$ at $0.05 \mathrm{~atm}$ for $6 \mathrm{~h}$ before the measurement began.

Fluorescent paper sheets or Eu-BC were taken under an AGL-9406 UV lamp for excitation at $256 \mathrm{~nm}$. The ultraviolet light absorption of the samples was measured by solid-state ultraviolet spectrophotometer (UV-2450, SHIMADZU, Kyoto, Japan). The fluorescence spectra of the samples were recorded by a steady-state transient fluorescence spectrometer (FluoroMax-4, HORIBA Jobin Yvon, Longjumeau, France).

The Eu content of the paper was measured by an atomic absorption spectrometer (Z-2000, Hitachi, Tokyo, Japan). The surface morphologies of unmodified BC, Eu-BC, Eu-BC fluorescent papers were observed by a scanning electron microscope (SEM) (Merlin, Zeiss, Munich, Germany); X-ray photoelectron spectroscopy (XPS) was conducted on the fluorescent paper by a X-ray photoelectron spectrometer (Kratos Axis Ulra DLD, Kratos Analytical, Manchester, UK) to analyze the valence and binding energy of the Eu ions. 


\section{Results and Discussion}

\subsection{Characterization of Eu-BC and Fluorescent Paper}

Bacterial cellulose (BC) is a natural cellulosic material with nanoporous structure, which provides the advantages to stably support functional nanoparticles. The BC used in this study was prepared by static fermentation method instead of agitated method because BC prepared by static method provides paper with better mechanical properties [21]. The BC had a specific surface area of $41.69 \mathrm{~m}^{2} / \mathrm{g}$ and a pore volume of $0.1598 \mathrm{~cm}^{3} / \mathrm{g}$ (Table 1 ). As can be seen from the SEM image (Figure 1a), BC is composed of ultrafine and reticular nanofibrils demonstrating a large specific surface area. Eu-BC complex was prepared by adsorbing $\mathrm{Eu}^{3+}$ onto the nanoporous structure of BC. The total Eu content of Eu-BC was $32.3 \mathrm{wt} \%$ (Table 1), which suggested that the Eu ions were successfully adsorbed onto BC. The XPS spectrum of Eu-BC showed that the binding energies of the two peaks were close to 1126 and $1155 \mathrm{eV}$, which belonged to the $\mathrm{Eu}^{3+}$ valence state and suggested that all the Eu in BC was still in $\mathrm{Eu}^{3+}$ forms (Figure 2a). The XPS spectrum indicated that $\mathrm{Eu}^{3+}$ ions were successfully coordinated with $\mathrm{BC}$ to form a Eu-BC complex. Specific surface area and pore volume of Eu-BC decreased greatly to $6.84 \mathrm{~m}^{2} / \mathrm{g}$ and $0.0214 \mathrm{~cm}^{3} / \mathrm{g}$, indicating $\mathrm{Eu}^{3+}$ formed uniform complex with $\mathrm{BC}$ and occupied most of pores on BC surface. As demonstrated by SEM image (Figure 1b), Eu-BC complex was evenly distributed or dispersed among the $\mathrm{BC}$ matrix. Eu-BC complex was evenly dispersed because of the nanoporous structure of BC, and it also indicated the formation of nanosized complex particles.

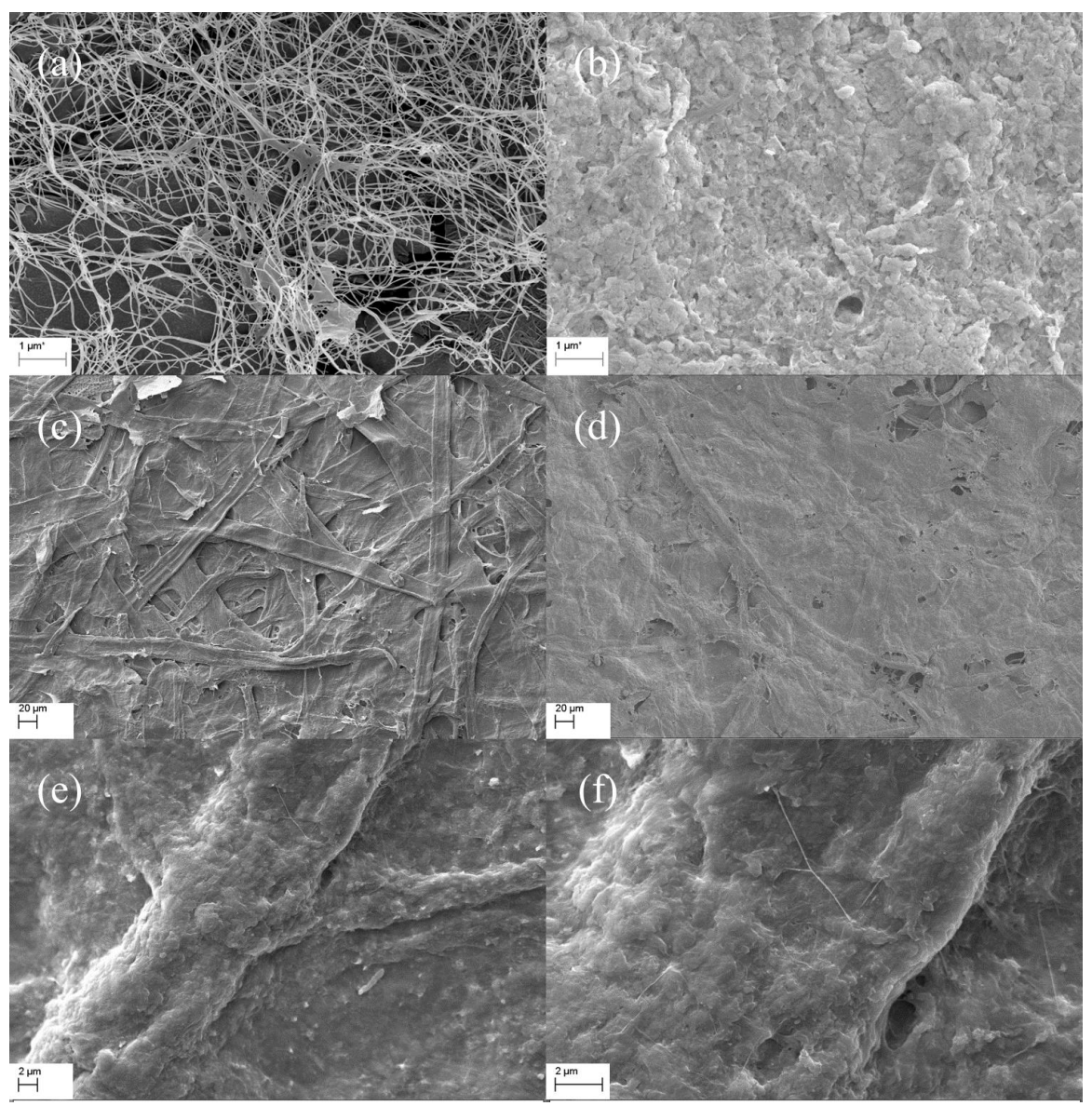

Figure 1. SEM images of (a) unmodified BC, (b) Eu-BC, (c) paper sheet made from sugarcane bagasse pulp, (d) Eu-BC fluorescent paper, and the cellulosic fibers on Eu-BC fluorescent paper at (e) $2 \mathrm{~K} \times$ magnification and at (f) $5 \mathrm{~K} \times$ magnification. 
The Bleached sugarcane bagasse pulp (BSBP) was composited with Eu-BC to produce fluorescent papers with different Eu-BC contents. The Eu content in Eu-BC fluorescent paper as determined by atomic absorption spectrometry was proportional to the amount of Eu-BC added to the production of the fluorescent paper, demonstrating a uniform adsorption of Eu ions onto BC (Table 1). Most of the Eu elements in the fluorescent paper were still in the valence state of $3+$ (Figure $2 b$ ), facilitating the photofluorescence of the fluorescent paper. The fluorescent paper showed red fluorescence under ultraviolet light irradiation at $256 \mathrm{~nm}$ (Figure 3), indicating that the energy of ultraviolet light absorbed is effectively transferred to $\mathrm{Eu}^{3+}$ through the "antenna effect", making the fluorescent paper glow red [11-14]. It can be seen from the SEM images that almost all the bagasse fibers were uniformly covered by Eu-BC (Figure 1c-e). The reticular structure of BC can also be identified on fiber surface (Figure 1f).
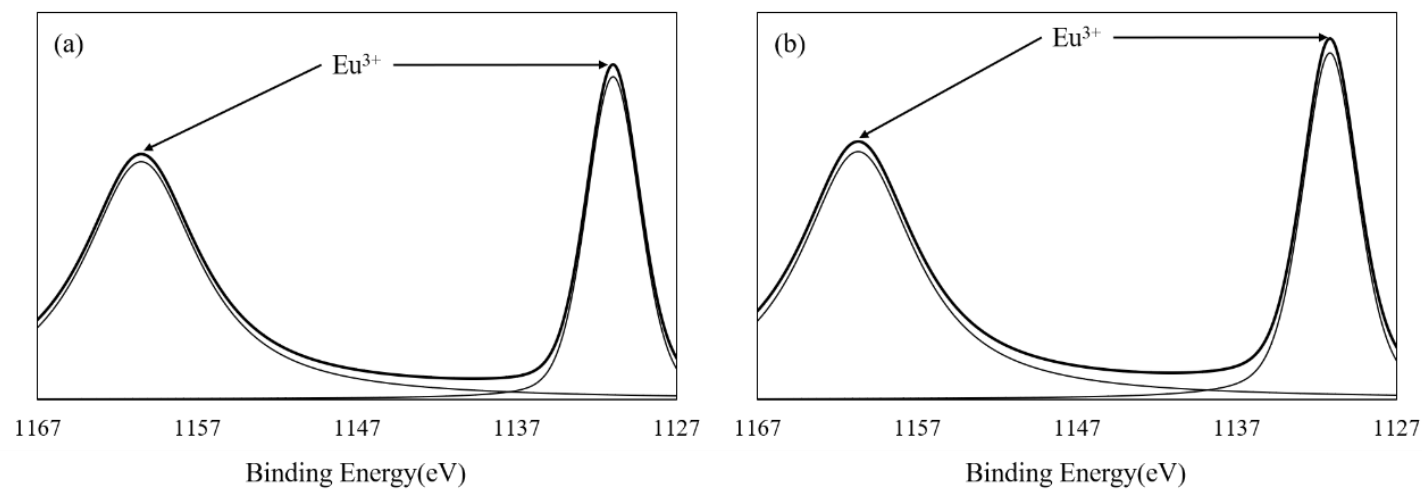

Figure 2. XPS spectra of (a) Eu-BC and (b) 20\% Eu-BC fluorescent paper.

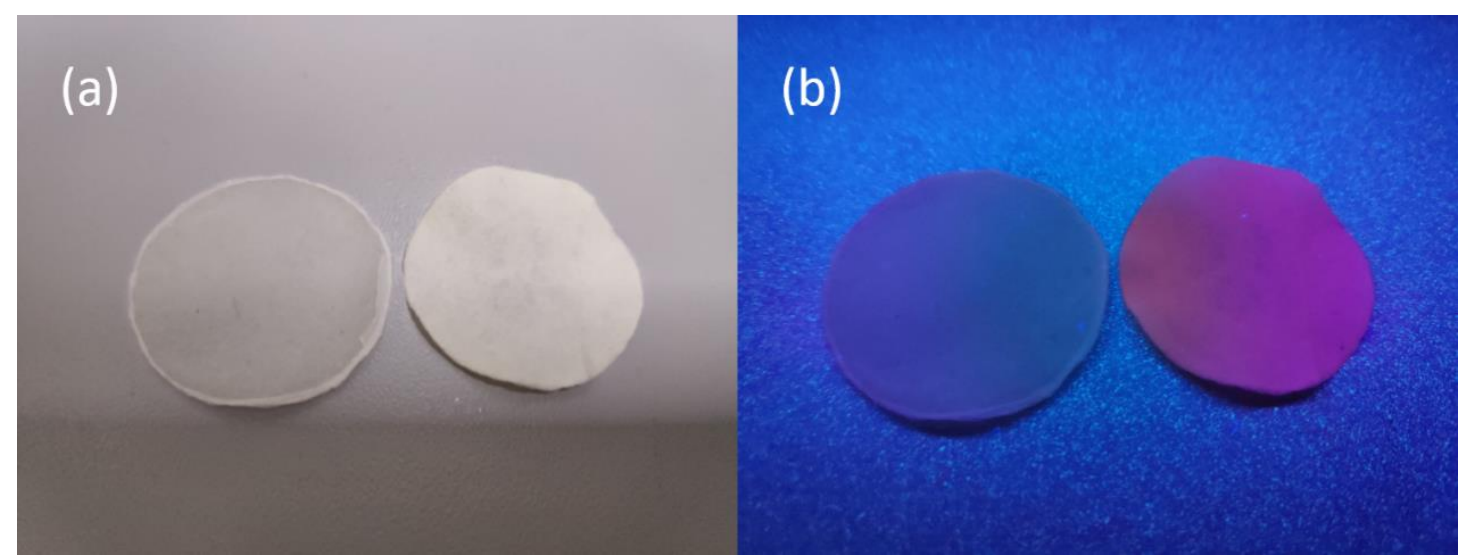

Figure 3. Photographs of 20\% BC paper (without Eu) and 20\% Eu-BC fluorescent paper (a) under visible light and (b) under ultraviolet light.

Table 1. Eu contents and BET parameters of BC, Eu-BC, and fluorescent paper sheets with different Eu-BC contents.

\begin{tabular}{|c|c|c|c|c|}
\hline Sample & Eu wt $\%$ & $\begin{array}{l}\text { Specific Surface } \\
\text { Area }\left(\mathrm{m}^{2} / \mathrm{g}\right)\end{array}$ & $\begin{array}{l}\text { Pore Volumn } \\
\qquad\left(\mathrm{cm}^{3} / \mathrm{g}\right)\end{array}$ & $\begin{array}{l}\text { Average Pore } \\
\text { Radius (nm) }\end{array}$ \\
\hline $\mathrm{BC}$ & 0 & 41.69 & 0.1598 & 15.81 \\
\hline Eu-BC & 32.30 & 6.84 & 0.0214 & 15.62 \\
\hline $1 \%$ Eu-BC fluorescent paper & 0.32 & 6.81 & 0.0991 & 79.84 \\
\hline $2 \%$ Eu-BC fluorescent paper & 0.88 & - & - & - \\
\hline $5 \%$ Eu-BC fluorescent paper & 1.53 & 3.17 & 0.0024 & 5.81 \\
\hline $10 \%$ Eu-BC fluorescent paper & 2.44 & - & - & - \\
\hline $20 \%$ Eu-BC fluorescent paper & 7.74 & 12.12 & 0.0430 & 14.74 \\
\hline
\end{tabular}




\subsection{Photofluorescent Properties of Eu-BC and Eu-BC Paper}

As can be seen from Figure 4, there were two peaks in the Eu-BC excitation spectrum, $305 \mathrm{~nm}$ and $312 \mathrm{~nm}$ (Figure 4a). The $305 \mathrm{~nm}$ wavelength was selected to excite fluorescent papers of different $\mathrm{Eu}-\mathrm{BC}$ contents to obtain a fluorescence emission spectrum. With the excitation at $305 \mathrm{~nm}$ wavelength, the fluorescent paper produced radiation emission at $605 \mathrm{~nm}$ and $618 \mathrm{~nm}$ (Figure 4b), which should correspond to $\mathrm{Eu}^{3+}$ magnetic dipole transition of ${ }^{5} \mathrm{D}_{0} \rightarrow{ }^{7} \mathrm{~F}_{1}$ and electric dipole transition of ${ }^{5} \mathrm{D}_{0} \rightarrow{ }^{7} \mathrm{~F}_{2}[1]$. The peaks of Figure $4 \mathrm{~b}$ suggested that the emission intensity of fluorescent paper below 5\% Eu-BC content increases with the increases of Eu-BC content. The emission intensity of fluorescent paper conducted no more increases when the EU-BC content in fluorescent paper was greater than 5\%.
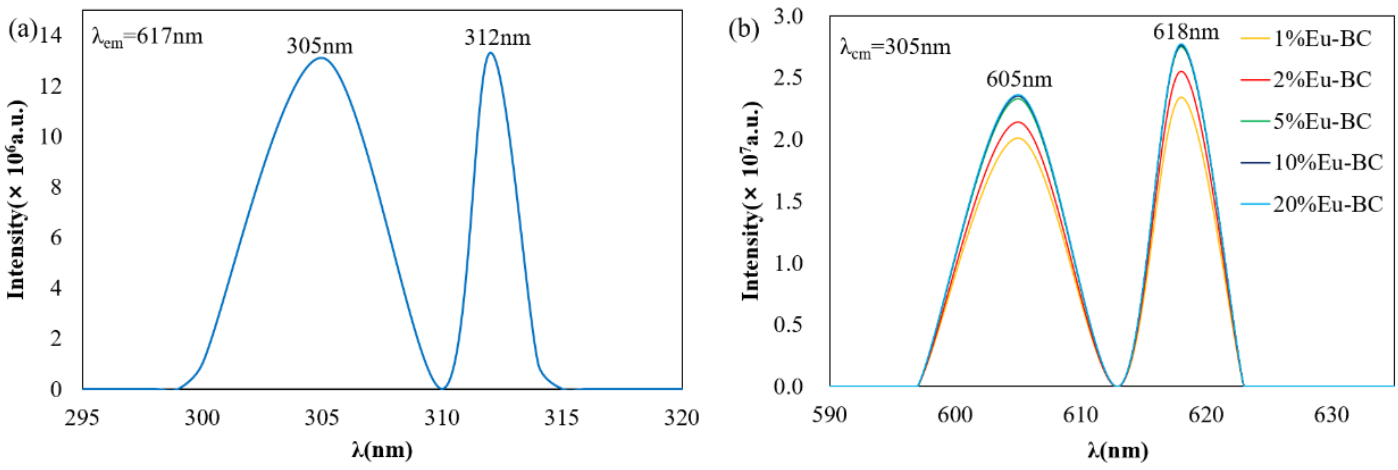

Figure 4. (a) Fluorescence excitation spectra of Eu-BC and (b) fluorescence emission spectra of fluorescent paper sheets with different Eu-BC contents.

By evaluating the solid-state ultraviolet absorption spectrum (Figure 5a), the fluorescent paper had two absorbance peaks at the wavelength of 230 and $280 \mathrm{~nm}$. The absorbance of $1 \%, 2 \%$, and $5 \%$ Eu-BC fluorescent paper successively increased with the increase of Eu-BC content. However, the absorbance of 5\%,10\%, and 20\% Eu-BC fluorescent paper remained almost unchanged. This result was consistent with the fluorescence excitation spectrum, showing that after Eu-BC content exceeds 5\% the fluorescent property would not change for the fluorescent paper.
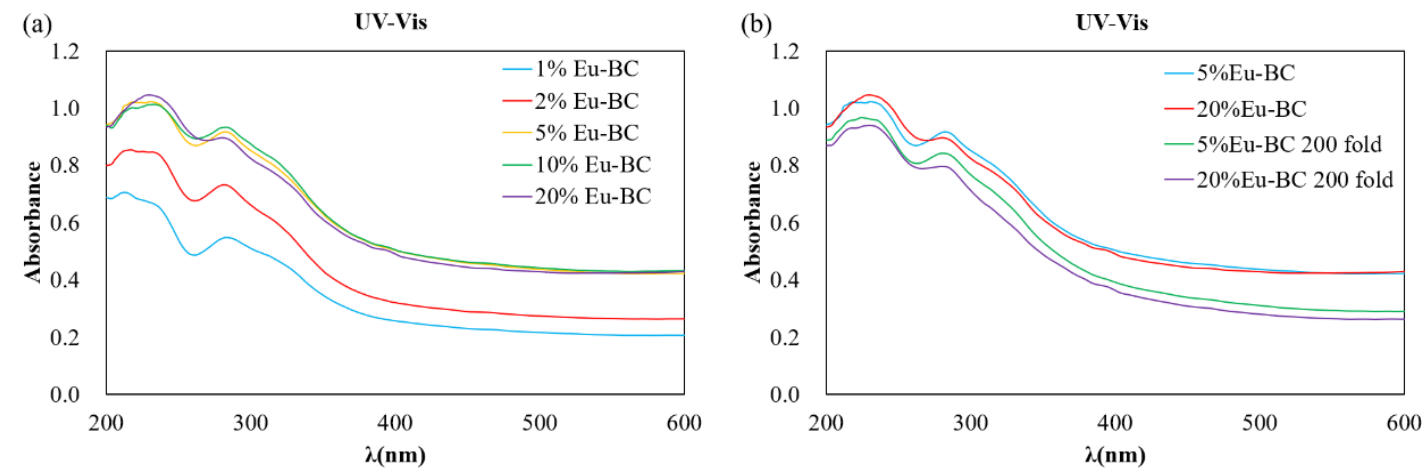

Figure 5. (a) UV-Vis absorbance spectra of fluorescent paper sheets with different Eu-BC contents and (b) changes in UV-Vis spectra after fluorescent paper was folded 200 times.

The structure of 5\% Eu-BC and 20\% Eu-BC fluorescent paper were shown in Figure 6. For the 5\% Eu-BC paper, the reticular structure of BC can still be seen, but for the $20 \%$ Eu-BC paper, the paper was all covered with Eu-BC complex packed full with Eu elements, in which some Eu-BC complexes were observed to be stacked with each other. Many Eu-BC complexes or Eu particles were squeezed or buried inside the middle of the composite, which made them hard to be stimulated by ultraviolet light. This statement can be proved by the surface area, pore volume, and pore size data of EuBC paper (Table 1). For 1\% EuBC paper, the cellulosic fibers were not entirely covered with EuBC, so it 
had relatively high pore volume and pore size; for 5\% EuBC paper, the cellulosic fibers were largely covered with EuBC, so its pore volume and pore size decreased; for $20 \%$ EuBC paper, many EuBC stacked together, building some now pores between layers leading to the increase in pore volume and pore size (Table 1). Similar results were also found in the studies of poly(acrylonitrile)/Eu ${ }^{3+}$ complex that high $\mathrm{Eu}^{3+}$ does not necessary lead to improved emission intensity due to the stacking of emission centers [1]. This explains the fluorescence intensity or ultraviolet absorbance remaining constant when Eu-BC is over 5\%. It also indicated that $5 \%$ is the most economical amount for Eu-BC to composite with cellulosic fibers.

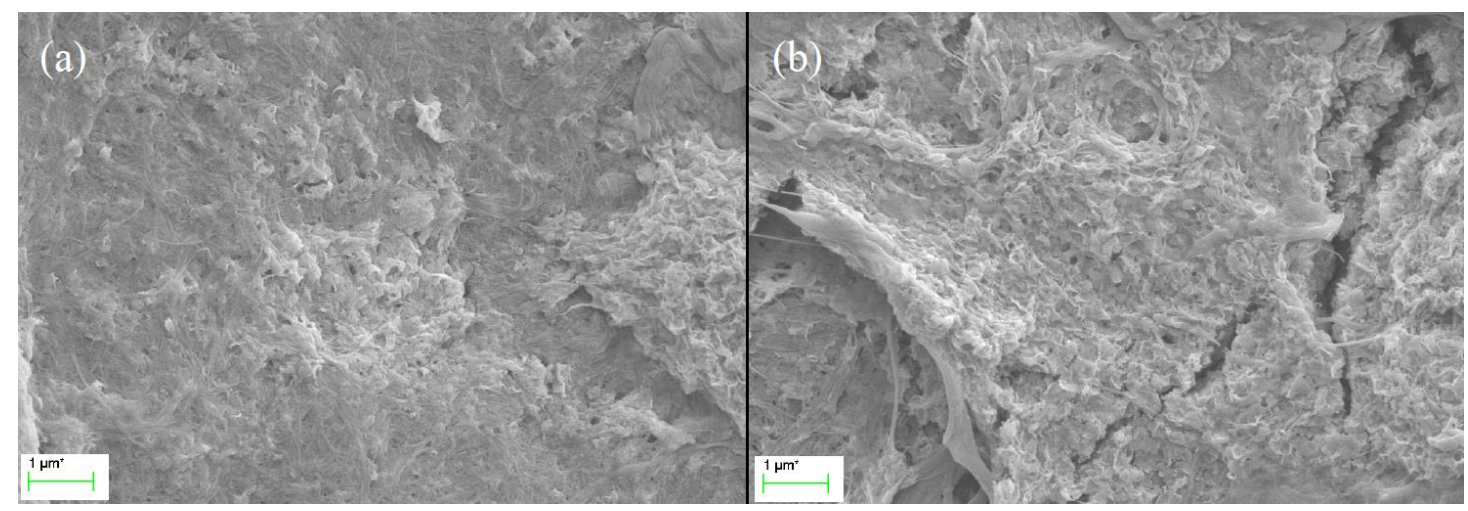

Figure 6. SEM images of (a) 5\% Eu-BC fluorescent paper and (b) 20\% Eu-BC fluorescent paper at $10 \mathrm{~K} \times$ magnification.

\subsection{Stability and Durability of Fluorescent Paper}

To investigate the stability and durability of fluorescent paper, $5 \% \mathrm{Eu}-\mathrm{BC}$ fluorescent paper and $20 \% \mathrm{Eu}-\mathrm{BC}$ fluorescent paper were repeatedly folded 200 times. From the ultraviolet absorbance spectrum in Figure $5 b$, it can be found that the absorbance peaks decreased only slightly after folding 200 times. The absorbance of $5 \%$ Eu-BC fluorescent paper decreased by only 0.05 after 200 folds, while the $20 \% \mathrm{Eu}-\mathrm{BC}$ paper decreased by nearly 0.1 . The fluorescence intensity at $618 \mathrm{~nm}$ emission changes after the folding of the fluorescent paper were shown in Figure 7. The intensity of the fluorescent paper only decreased by $\sim 0.7 \%$ after 200 folds. This result suggested that the fluorescent paper has great stability and durability, and 5\% Eu-BC fluorescent paper is even better than the 20\% Eu-BC fluorescent paper. It suggested that the nanoporous and reticular structure of $\mathrm{BC}$ can help to form very stable complex with Eu ions, by preventing the Eu particles from leaching or aggregating.

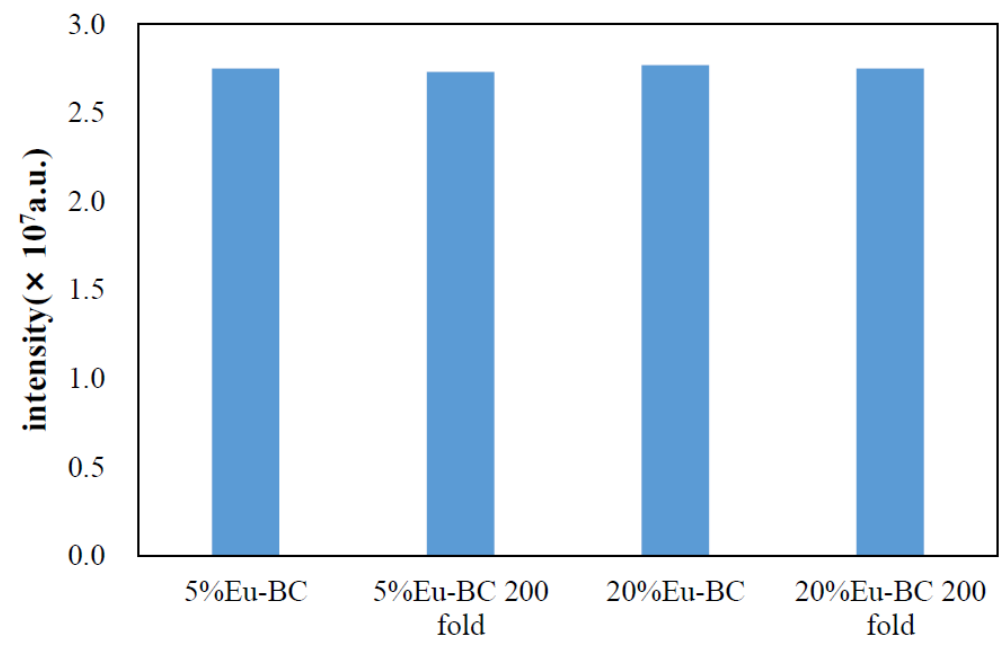

Figure 7. Changes of fluorescence emission spectra at $618 \mathrm{~nm}$ for Eu-BC fluorescent paper after 200 foldings. 


\subsection{Comparison of Eu-BC Fluorescent Paper with Other Composite Fluorescent Materials}

We mainly compared the fluorescence intensity of different substrates complexing with $\mathrm{Eu}^{3+}$ ions, such as CMC [12], polydimethylsiloxane (PDMS) [34], $\beta$-diketone,4-imidazol-4,4,4-trifluorobutane-

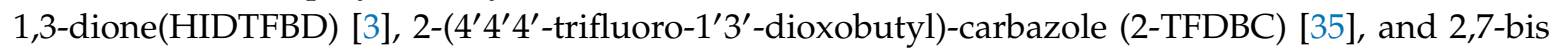
( $4^{\prime} 4^{\prime} 4^{\prime}$-trifluoro-1'3'-dioxobutyl)-carbazole (2,7-BTFDBC) [35]. The highest fluorescent emission intensity of the Eu-BC fluorescent paper in this study can reach $2.77 \times 10^{7}$ a.u., showing higher value than many of the Eu-ligand complex fluorescent materials; the Eu-BC fluorescent paper also had a lowest Eu mass ratio among all showing its high efficiency (Table 2). This may be due to the high surface area of $\mathrm{BC}$ providing large numbers of chelating centers for $\mathrm{Eu}^{3+}$ and the nanoporous structure of $\mathrm{BC}$ providing uniform distribution of Eu elements. In addition, our Eu-BC fluorescent paper maintained good fluorescence performance after 200 folds. These comparisons with similar studies demonstrate the high efficiency and great durability for our Eu-BC fluorescent paper.

Table 2. Comparison of composites with different substrate loadings of $\mathrm{Eu}^{3+}$ ions.

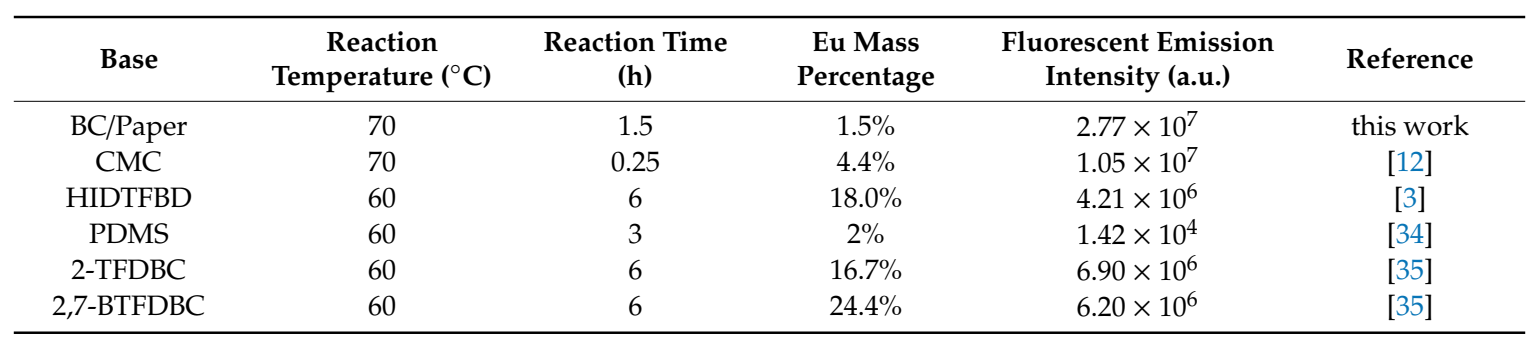

\section{Conclusions}

Fluorescent paper was prepared by compositing the Eu-BC complex with sugarcane bagasse pulps (BSBP). The fluorescent paper demonstrated a great fluorescent property and efficiency, i.e., having very low Eu mass content but high fluorescent intensity, compared to many of its counterpart fluorescent materials based on Eu/ligand complex. The ultraviolet absorbance or the fluorescent intensity of the Eu-BC fluorescent paper increased with the increase of Eu-BC content but remained little changed after Eu-BC content was higher than 5\%, which was due to excessive Eu-BC complexes stacking with each other without effective irritation by ultraviolet light. After 200 times of folding, the fluorescence intensity of fluorescent paper decreased by only $0.7 \%$, which suggested that the Eu-BC fluorescent paper has very good stability and durability. The high durability of the fluorescent paper can be attributed to the nanoporous or reticular structure of $\mathrm{BC}$ stabilizing the Eu particles.

Author Contributions: Conceptualization, Z.X.; methodology, Z.X.; investigation, M.Z. and X.W.; resources, T.S.; writing-original draft preparation, M.Z.; writing—review and editing, Z.X. and Z.H.; supervision, F.L.; project administration, Z.X.; funding acquisition, Z.X. and F.L.

Funding: This work was supported by Guangzhou Science and Technology Program (Key Scientific Research Project 201707020011), the National Natural Science Foundation of China (31600470), Guangzhou Science and Technology Program (General Scientific Research Project 201707010053), and Guangdong Province Science Foundation for Cultivating National Engineering Research Center for Efficient Utilization of Cellulosic fibers (2017B090903003).

Acknowledgments: The authors would like to thank Nanjing High Tech University Biological Technology Research Institute Co., Ltd. for providing the bacterial cellulose.

Conflicts of Interest: The authors declare no conflict of interest.

\section{References}

1. Tang, S.; Shao, C.; Liu, Y.; Mu, R. Electrospun nanofibers of poly(acrylonitrile)/Eu3+ and their photoluminescence properties. J. Phys. Chem. Solid. 2010, 71, 273-278. [CrossRef]

2. Sabbatini, N.; Guardigli, M.; Lehn, J.M. Luminescent lanthanide complexes as photochemical supramolecular devices. Coord. Chem. Rev. 1993, 123, 201-228. [CrossRef] 
3. Wang, H.; He, P.; Yan, H.; Shi, J.; Gong, M. A novel europium(III)-imidazol-diketonate-phenanthroline complex as a red phosphor applied in LED. Inorg. Chem. Commun. 2011, 14, 1183-1185. [CrossRef]

4. Reyes, R.; Cremona, M.; Teotonio, E.E.S.; Brito, H.F.; Malta, O.L. Voltage color tunable OLED with (Sm,Eu)- $\beta$-diketonate complex blend. Chem. Phys. Lett. 2004, 396, 54-58. [CrossRef]

5. Teotonio, E.; Brito, H.F.; da Cunha Felinto, M.C.F.; Thompson, L.C.; Young, V.G.; Malta, O.L. Preparation, crystal structure and optical spectroscopy of the rare earth complexes (RE3 ${ }^{+}=\mathrm{Sm}, \mathrm{Eu}, \mathrm{Gd}$ and $\mathrm{Tb}$ ) with 2-thiopheneacetate anion. J. Mol. Struct. 2005, 751, 85-94. [CrossRef]

6. Reineke, T.M.; Eddaoudi, M.; Fehr, M.; Kelly, D.; Yaghi, O.M. From condensed lanthanide coordination solids to microporous frameworks having accessible metal sites. J. Am. Chem. Soc. 1999, 121, 1651-1657. [CrossRef]

7. Ma, L.; Evans, O.R.; Foxman, B.M.; Lin, W. Luminescent lanthanide coordination polymers. Inorg. Chem. 1999, 38, 5837-5840. [CrossRef]

8. Seo, J.S.; Whang, D.; Lee, H.; Jun, S.I.; Oh, J.; Jeon, Y.J.; Kim, K. A homochiral metal-organic porous material for enantioselective separation and catalysis. Nature 2000, 404, 982-986. [CrossRef]

9. Verlan, V.I.; Iovu, M.S.; Culeac, I.; Nistor, Y.H.; Turta, C.I.; Zubareva, V.E. Photoluminescence properties of $\mathrm{PVP} / \mathrm{Tb}(\mathrm{TTA})_{2}(\mathrm{Ph} 3 \mathrm{PO})_{2} \mathrm{NO}_{3}$ nanocomposites. J. Non-Crystalline Solid. 2013, 360, 21-25. [CrossRef]

10. Cui, G.; Chen, S.; Jiang, B.; Zhang, Y.; Qiu, N.; Satoh, T.; Kakuchi, T.; Duan, Q. Synthesis and characterization of novel thermoresponsive fluorescence complexes based on copolymers with rare earth ions. Optic. Mater. 2013, 35, 2250-2256. [CrossRef]

11. Ye, J.; Li, W.; Xiong, J. Relationship Between Size as Well as Size Distribution and Fluorescence Properties of CMC /Eu Complex Nanoparticles Synthesized at Different pH Values. J. South China Univ. Technol. 2014, 42, 73-78.

12. Ye, J.; Wang, B.; Xiong, J. Effect of Eu3+ Concentration on the Structure and Fluorescence Quenching of Carboxymethyl Cellulose /Eu(III) Nanoparticles. Polym. Mater. Sci. Eng. 2016, 32, 32-37.

13. Ye, J.; Li, W.; Xiong, J. Properties of Carboxyl-Containing Cellulose Derivatives/ Rare Earth Ions Nanocomposites. J. South China Univ. Technol. 2017, 45, 48-56.

14. Ye, J.; Guo, Y.; Xiong, J. Effect of $\mathrm{pH}$ on size and dispersion of CMC/Eu nanocomposites with high fluorescence intensity. Funct. Mater. 2012, 18, 2541-2545.

15. Dai, H.; Wong, E.W.; Lu, Y.Z.; Fan, S.; Lieber, C.M. Synthesis and characterization of carbide nanorods. Nature 1995, 375, 769-772. [CrossRef]

16. Dong, S.; Roman, M. Fluorescently Labeled Cellulose Nanocrystals for Bioimaging Applications. J. Am. Chem. Soc. 2007, 129, 13810-13811. [CrossRef] [PubMed]

17. Wu, W.; Huang, F.; Pan, S.; Mu, W.; Meng, X.; Yang, H.; Xu, Z.; Ragauskas, A.J.; Deng, Y. Thermo-responsive and fluorescent cellulose nanocrystals grafted with polymer brushes. J. Mater. Chem. A 2015, 3, 1995-2005. [CrossRef]

18. Díez, I.; Eronen, P.; Österberg, M.; Linder, M.B.; Ikkala, O.; Ras, R.H.A. Functionalization of Nanofibrillated Cellulose with Silver Nanoclusters: Fluorescence and Antibacterial Activity. Macromol. Biosci. 2011, 11, 1185-1191. [CrossRef]

19. Niu, Q.; Gao, K.; Wu, W. Cellulose nanofibril based graft conjugated polymer films act as a chemosensor for nitroaromatic. Carbohydr. Polym. 2014, 110, 47-52. [CrossRef]

20. Xiang, Z.; Jin, X.; Liu, Q.; Chen, Y.; Li, J.; Lu, F. The reinforcement mechanism of bacterial cellulose on paper made from woody and non-woody fiber sources. Cellulose 2017, 24, 5147-5156. [CrossRef]

21. Xiang, Z.; Liu, Q.; Chen, Y.; Lu, F. Effects of physical and chemical structures of bacterial cellulose on its enhancement to paper physical properties. Cellulose 2017, 24, 3513-3523. [CrossRef]

22. Zhang, X.; Chen, W.; Lin, Z.; Yao, J.; Tan, S. Preparation and Photocatalysis Properties of Bacterial Cellulose/TiO2Composite Membrane Doped with Rare Earth Elements. Synth. React. Inorg. Metal-Organic Nano-Metal Chem. 2011, 41, 997-1004. [CrossRef]

23. Yang, Z.; Chen, S.; Hu, W.; Yin, N.; Zhang, W.; Xiang, C.; \& Wang, H. Flexible luminescent CdSe/bacterial cellulose nanocomoposite membranes. Carbohydr. Polym. 2012, 88, 173-178. [CrossRef]

24. Chen, L.F.; Huang, Z.H.; Liang, H.W.; Yao, W.T.; Yu, Z.-Y.; Yu, S.H. Flexible all-solid-state high-power supercapacitor fabricated with nitrogen-doped carbon nanofiber electrode material derived from bacterial cellulose. Energ. Environ. Sci. 2013, 6, 3331. [CrossRef] 
25. Huang, Y.; Wang, T.; Ji, M.; Yang, J.; Zhu, C.; Sun, D. Simple preparation of carbonized bacterial cellulose-Pt composite as a high performance electrocatalyst for direct methanol fuel cells (DMFC). Mater. Lett. 2014, 128, 93-96. [CrossRef]

26. Kwon, H.; Samain, F.; Kool, E.T. Fluorescent DNAs printed on paper: Sensing food spoilage and ripening in the vapor phase. Chem. Sci. 2012, 3, 2542. [CrossRef]

27. Ma, Y.; Li, H.; Peng, S.; Wang, L. Highly Selective and Sensitive Fluorescent Paper Sensor for Nitroaromatic Explosive Detection. Anal. Chem. 2012, 84, 8415-8421. [CrossRef]

28. Su, L.; Yang, L.; Sun, Q.; Zhao, T.; Liu, B.; Jiang, C.; Zhang, Z. A ratiometric fluorescent paper sensor for consecutive color change-based visual determination of blood glucose in serum. New J. Chem. 2018, 42, 6867-6872. [CrossRef]

29. Zhang, W.; Feng, X.; Zhu, Y.; Wei, X. Study on the Stability and Color Property of Fluorescent Ink-jet Ink. Lect. Notes Elect. Eng. 2015, 369, 919-925.

30. Hou, X.; Ke, C.; Bruns, C.J.; McGonigal, P.R.; Pettman, R.B.; Stoddart, J.F. Tunable solid-state fluorescent materials for supramolecular encryption. Nat. Commun. 2015, 6, 6884. [CrossRef]

31. Purington, E.; Bousfield, D.; Gramlich, W.M. Fluorescent dye adsorption in aqueous suspension to produce tagged cellulose nanofibers for visualization on paper. Cellulose 2019, 26, 5117-5131. [CrossRef] [PubMed]

32. Xiang, Z.; Chen, Y.; Liu, Q.; Lu, F. A highly recyclable dip-catalyst produced from palladium nanoparticle-embedded bacterial cellulose and plant fibers. Green Chem. 2018, 20, 1085-1094. [CrossRef]

33. Wu, X.; Xiang, Z.; Song, T.; Qi, H. Wet-strength agent improves recyclability of dip-catalyst fabricated from gold nanoparticle-embedded bacterial cellulose and plant fibers. Cellulose 2019, 26, 3375-3386. [CrossRef]

34. Xu, J.; Huang, X.; Zhou, N.; Zhang, J.; Bao, J.C.; Lu, T.; Li, C. Synthesis, XPS and fluorescence properties of $\mathrm{Eu}^{+}{ }^{+}$complex with polydimethylsiloxane. Mater. Lett. 2004, 58, 1938-1942. [CrossRef]

35. He, P.; Wang, H.H.; Liu, S.G.; Shi, J.X.; Wang, G.; Gong, M.L. Visible-Light Excitable Europium(III) Complexes with 2,7-Positional Substituted Carbazole Group-Containing Ligands. Inorg. Chem. 2009, 48, 11382-11387. [CrossRef] [PubMed]

(C) 2019 by the authors. Licensee MDPI, Basel, Switzerland. This article is an open access article distributed under the terms and conditions of the Creative Commons Attribution (CC BY) license (http://creativecommons.org/licenses/by/4.0/). 